\title{
Coronary artery bypass grafting in familial hypercholesterolemia
}

Familial hypercholesterolemia is an autosomal dominant disorder caused by a mutation of the gene for the low-density lipoprotein receptor and is characterized by rapidly progressing coronary atherosclerosis. We assessed the long-term results of coronary artery bypass grafting performed during the past 13 years in 62 patients with heterozygous familial hypercholesterolemia, whose mean plasma total and low-density lipoprotein cholesterol level was $327 \mathrm{mg} / \mathrm{dl}$ and $238 \mathrm{mg} / \mathrm{dl}$, respectively. The patients had severe coronary atherosclerosis, with coronary stenosis index of 19.7 , and the prevalence of extracoronary atherosclerotic lesions was $27 \%$. Sixty-one patients underwent successful coronary artery bypass operation, with an average of 2.5 grafts, and the coronary stenosis index decreased to 7.1. After operation, all patients consumed a cholesterol-lowering diet and received drug therapy with pravastatin, probucol, or cholestyramine. Seven patients who were resistant to drug therapy were treated with plasma low-density lipoprotein apheresis. The cholesterol-lowering therapy reduced plasma total cholesterol level by 37\%, low-density lipoprotein cholesterol level by 42\%, and low-density lipoprotein/high-density lipoprotein cholesterol ratio by $37 \%(p<0.001)$. During the follow-up period (mean, 52 months; range, 10 to 157 months), there was no cardiac death, but three patients died of malignant disease. The actuarial survival rate was $95 \%$ at 5 years and $89 \%$ at 12 years after operation. The actuarial freedom from recurrent angina was $90 \%$ at 5 years and $53 \%$ at 11 years after operation. Four patients underwent reoperation, an average of 8 years postoperatively, because of vein graft atherosclerosis. In spite of severe coronary atherosclerosis, these patients with familial hypercholesterolemia showed good long-term outcome after coronary artery bypass operation. The present findings suggest that aggressive use of arterial grafts, intensive cholesterollowering drug therapy, and low-density lipoprotein apheresis may be useful in patients with familial hypercholesterolemia. (J THORAC CARDIOVASC SURG 1995;109:364-9)

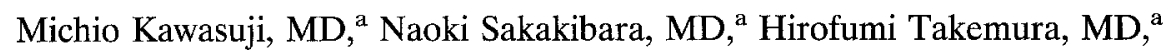
Yasushi Matsumoto, MD, ${ }^{a}$ Hiroshi Mabuchi, MD, ${ }^{\mathrm{b}}$ and Yoh Watanabe, MD, ${ }^{\mathrm{a}}$ Kanazawa, Japan

$\mathrm{H}$ for coronary atherosclerosis. Familial hypercholesterolemia $(\mathrm{FH})$ is an autosomal dominant disorder caused by a mutation of the gene for the low-density

From the Department of Surgery ${ }^{\mathrm{a}}$ and Department of Internal Medicine, ${ }^{b}$ Kanazawa University School of Medicine, Kanazawa, Japan.

Received for publication Feb. 10, 1994.

Accepted for publication May 31, 1994.

Address for reprints: Michio Kawasuji, MD, Department of Surgery, Kanazawa University School of Medicine, Takaramachi 13-1, Kanazawa 920, Japan.

Copyright $@ 1995$ by Mosby-Year Book, Inc.

$0022-5223 / 95 \$ 3.00+0 \quad \mathbf{1 2} / \mathbf{1} / \mathbf{5 8 2 0 3}$ lipoprotein (LDL) receptor. ${ }^{1} \mathrm{FH}$, which is characterized by high plasma level of cholesterol and the development of cutaneous and tendon xanthoma, is frequently associated with premature coronary heart disease. ${ }^{1-3}$ Homozygous FH occurs in approximately one out of every 1 million persons and usually causes death before the patient reaches the age of $30 .^{1,4}$ Heterozygous $\mathrm{FH}$ is a more common disorder, occurring in approximately one out of every 500 persons in Japan and in Western countries. ${ }^{1,3,5}$ Coronary stenosis usually develops in patients with heterozygous $\mathrm{FH}$ in the second decade of life and progresses more rapidly than that in the general population. ${ }^{6}$ About $70 \%$ of patients with heterozy- 


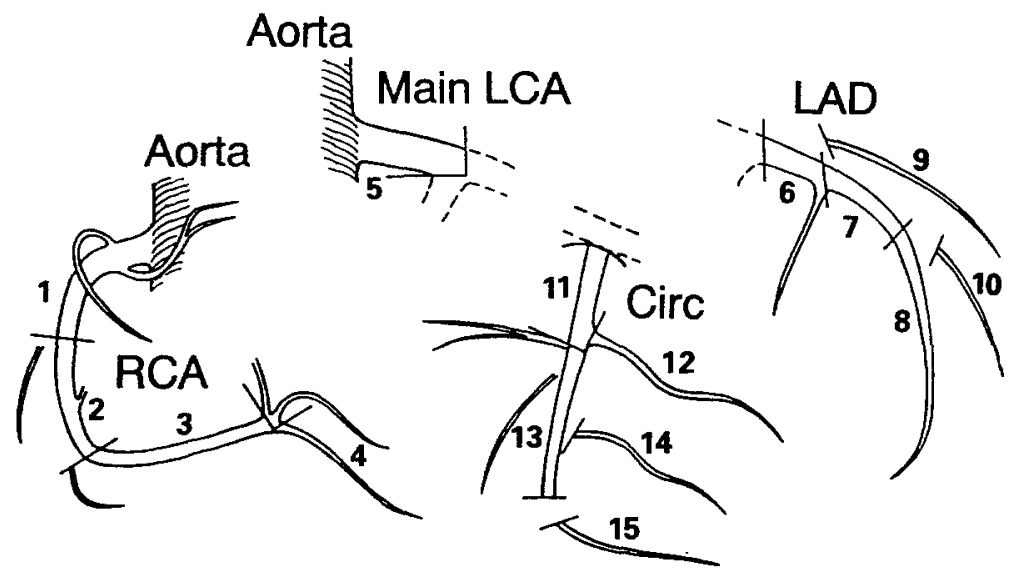

\section{Coronary Stenosis Index \\ Grade 0 : no significant stenosis \\ Grade 1 : less than $25 \%$ stenosis \\ Grade $2: 25 \%$ - $49 \%$ stenosis \\ Grade $3: 50 \%$ - $74 \%$ stenosis \\ Grade $4: 75 \%$ or more stenosis}

Fig. 1. Coronary artery segments and coronary stenosis index.

gous FH in $\mathrm{Japan}^{3}$ and in European countries ${ }^{2,7}$ die of coronary heart disease.

Coronary artery bypass grafting operation (CABG) has been performed in patients with $\mathrm{FH}$ to relieve myocardial ischemia and to diminish morbidity and mortality of myocardial infarction, ${ }^{8,9}$ and there is concern regarding the long-term prognosis after CABG. Because of the rapid progression of coronary atherosclerosis in patients with $\mathrm{FH}$, a surgical strategy and intensive cholesterol-lowering therapy are necessary. This article includes our 13-year experience with CABG in 62 consecutive patients with heterozygous $\mathrm{FH}$ and their long-term outcome. The findings in extreme cases have important implications for the surgical and medical treatment of patients with coronary atherosclerosis.

\section{Patients and methods}

Sixty-two patients with FH underwent CABG between June 1980 and May 1993 at Kanazawa University Medical Center. The patient group included 46 men and 16 women who ranged in age from 35 to 74 years, with a mean age of 54 years ( 52 years for men and 61 years for women). FH was diagnosed according to the following two criteria: primary hypercholesterolemia (above $230 \mathrm{mg} / \mathrm{dl}$, regardless of age group) with tendon xanthoma and primary hypercholesterolemia with or without tendon xanthoma in a first-degree relative of patients with $\mathrm{FH}$. All of the patients had heterozygous FH. Data for these patients were obtained before the introduction of cholesterol- lowering drug therapy. The mean level of plasma total cholesterol was $327 \mathrm{mg} / \mathrm{dl}$, LDL cholesterol was $238 \mathrm{mg} / \mathrm{dl}$, high-density lipoprotein (HDL) cholesterol was $36 \mathrm{mg} / \mathrm{dl}$, and triglyceride was $166 \mathrm{mg} / \mathrm{dl}$. Twenty-one (34\%) of the patients had hypertension, and $22(35 \%)$ had diabetes mellitus. Twenty-eight (45\%) of the patients had a history of remote myocardial infarction. One patient had onevessel coronary artery disease, 14 had two-vessel disease, 30 had three-vessel disease, and 17 had disease of the left main coronary artery. The extent and severity of the coronary stenotic changes were assessed by assigning scores to each of the 15 coronary artery segments, according to the classification of the American Heart Association Grading Committee. ${ }^{10} \mathrm{~A}$ normal coronary angiogram was graded 0 , stenosis of less than $25 \%$ was graded $1,25 \%$ to $49 \%$ stenosis was graded $2,50 \%$ to $74 \%$ stenosis was graded 3 , and $75 \%$ or more stenosis was graded 4 (Fig. 1). The coronary stenosis index was defined as the sum of these scores. ${ }^{11}$ The mean value of the coronary stenosis index before CABG was 19.7 ( 8 to 36$)$. Thirteen $(21 \%)$ of the patients showed coronary ectasia. The mean left ventricular ejection fraction was $0.61(0.21$ to 0.82$)$. Four $(6 \%)$ of the patients had supravalvular aortic stenosis, four $(6 \%)$ had a history of cerebral infarction, four $(6 \%)$ had an abdominal aortic aneurysm, and nine (15\%) had symptomatic peripheral arterial disease. CABG was performed with myocardial preservation with the administration of cold crystalloid potassium cardioplegic solution. Three patients underwent $\mathrm{CABG}$ and simultaneous or two-staged graft replacement of the abdominal aortic aneurysm. Coronary angiography was performed 1 month after CABG in 59 patients, and the coronary stenosis index was determined. The severity of coronary stenosis 
Table I. Changes in plasma lipids and coronary stenosis index

\begin{tabular}{ccccc}
\hline Factors & $\begin{array}{c}\text { Before } \\
\text { treatment }\end{array}$ & $\begin{array}{c}\text { After } \\
\text { treatment }\end{array}$ & Change & p Value \\
\hline $\begin{array}{c}\text { Total cholesterol } \\
\text { (mg/dl) }\end{array}$ & $327 \pm 62$ & $205 \pm 48$ & $-37 \%$ & $<0.001$ \\
$\begin{array}{c}\text { LDL cholesterol } \\
\text { (mg/dl) }\end{array}$ & $238 \pm 71$ & $138 \pm 44$ & $-42 \%$ & $<0.001$ \\
$\begin{array}{c}\text { HDL cholesterol } \\
\text { (mg/dl) }\end{array}$ & $36 \pm 14$ & $32 \pm 12$ & $-11 \%$ & $\mathrm{NS}$ \\
$\begin{array}{c}\text { Triglyceride } \\
\text { (mg/dl) }\end{array}$ & $166 \pm 86$ & $119 \pm 72$ & $-29 \%$ & $<0.01$ \\
$\begin{array}{c}\text { Total/HDL } \\
\text { cholesterol }\end{array}$ & $10.5 \pm 4.4$ & $7.7 \pm 3.2$ & $-27 \%$ & $<0.001$ \\
$\begin{array}{c}\text { LDL/HDL } \\
\text { cholesterol }\end{array}$ & $7.5 \pm 3.8$ & $4.7 \pm 2.2$ & $-37 \%$ & $<0.001$ \\
$\begin{array}{c}\text { Coronary } \\
\text { stenosis index }\end{array}$ & $19.7 \pm 6.2$ & $7.1 \pm 4.3$ & $-64 \%$ & $<0.001$ \\
\hline
\end{tabular}

Values are mean \pm standard deviation.

was graded 0 when postoperative angiography indicated complete revascularization of the target coronary artery. After the operation, all of the patients received diet therapy and cholesterol-lowering drug therapy to reduce cholesterol level to less than $180 \mathrm{mg} / \mathrm{dl}$ and LDL cholesterol level to less than $130 \mathrm{mg} / \mathrm{dl}$. Cholesterol-lowering drugs included pravastatin, probucol, or cholestyramine. Seven $(11 \%)$ patients who were resistant to drug therapy received treatment with LDL apheresis. ${ }^{12}$ Patients with hypertension or diabetes received antihypertensive or antidiabetic diet and drug therapy as well. The average duration of follow up after the initial operation was 52 months (range, 10 to 157 months). Actuarial freedom from recurrent angina and actuarial survival after $C A B G$ were calculated by the Kaplan-Meier method. Cumulative data are expressed as mean \pm standard deviation. Continuous variables were analyzed by Student's $t$ test to detect significant $(p<0.05)$ differences between the measured variables.

\section{Results}

Sixty-one (98\%) of the patients underwent successful CABG, and the average number of grafts per patient was 2.5. Twenty-seven patients received saphenous vein grafts only, but, beginning in 1986, 39 patients received arterial grafts, including 44 internal thoracic arteries and 11 right gastroepiploic arteries. Eight $(13 \%)$ of the patients had severe atherosclerosis of the ascending aorta. Perioperative myocardial infarction developed in two patients but was successfully treated with intraaortic balloon pumping. One patient died of graft-versus-host disease resulting from a blood transfusion. All but two patients became free of angina after the operation. The overall graft patency rate in the 59 patients after CABG was $94 \%$; this rate was $100 \%$ for all 44 internal thoracic arteries and 10 of the gastroepip-
Table II. Changes in plasma lipids and coronary stenosis index in seven patients with $\mathrm{FH}$ who underwent $C A B G$ and $L D L$ apheresis

\begin{tabular}{ccccc}
\hline Factors & $\begin{array}{c}\text { Before } \\
\text { treatment }\end{array}$ & $\begin{array}{c}\text { After } \\
\text { treatment }\end{array}$ & Change & $p$ Value \\
\hline $\begin{array}{c}\text { Total cholesterol } \\
(\mathrm{mg} / \mathrm{dl})\end{array}$ & $392 \pm 58$ & $158 \pm 26$ & $-60 \%$ & $<0.001$ \\
$\begin{array}{c}\text { LDL cholesterol } \\
(\mathrm{mg} / \mathrm{dl})\end{array}$ & $326 \pm 58$ & $107 \pm 22$ & $-67 \%$ & $<0.001$ \\
$\begin{array}{c}\text { HDL cholesterol } \\
(\mathrm{mg} / \mathrm{dl})\end{array}$ & $38 \pm 10$ & $36 \pm 6$ & $-5 \%$ & $\mathrm{NS}$ \\
$\begin{array}{c}\text { Triglyceride } \\
(\mathrm{mg} / \mathrm{dl})\end{array}$ & $160 \pm 96$ & $75 \pm 49$ & $-53 \%$ & $<0.05$ \\
$\begin{array}{c}\text { Total/HDL } \\
\text { cholesterol }\end{array}$ & $10.7 \pm 2.1$ & $4.5 \pm 1.1$ & $-58 \%$ & $<0.001$ \\
$\begin{array}{c}\text { LDL/HDL } \\
\text { cholesterol }\end{array}$ & $8.9 \pm 1.9$ & $3.1 \pm 0.9$ & $-65 \%$ & $<0.001$ \\
$\begin{array}{c}\text { Coronary } \\
\text { stenosis index }\end{array}$ & $22.9 \pm 5.2$ & $7.6 \pm 4.6$ & $-67 \%$ & $<0.001$ \\
\hline
\end{tabular}

Values are mean \pm standard deviation.

loic arteries and $91 \%$ for 98 saphenous vein grafts. The coronary stenosis index was reduced from 19.7 to 7.1 after operation $(p<0.001)$. After intensive cholesterol-lowering therapy, plasma total cholesterol, LDL cholesterol and triglyceride levels, and LDL/HDL cholesterol ratio decreased significantly, whereas HDL cholesterol level did not change (Table I). The decreases in plasma total and LDL cholesterol levels and LDL/HDL cholesterol ratio were more marked in the seven patients who underwent LDL apheresis (Table II).

During the follow-up period, angina recurred in nine patients $(15 \%)$. The cause of recurrence was vein graft atherosclerosis in five patients and progression of native coronary stenosis in four patients. One patient had non-fatal myocardial infarction. The actuarial freedom from recurrent angina was $89 \%$ at 5 years after operation and $53 \%$ at 11 years (Fig. 2). No difference was found in actuarial freedom from recurrent angina 5 years after the operation between patients who received saphenous vein grafts only and patients who received arterial grafts. Thirteen patients underwent repeat coronary angiography an average of 5 years after the operation. The overall late graft patency rate was $75 \%$; it was $100 \%$ for nine arterial grafts and $65 \%$ for 23 saphenous vein grafts. Three patients underwent percutaneous transluminal coronary angioplasty an average of 15 months after the operation. Four patients who received saphenous vein grafts only underwent reoperation because of vein graft atherosclerosis at an average of 8 years (range, 5 to 10 years) after the first operation. In these four patients, the coronary 


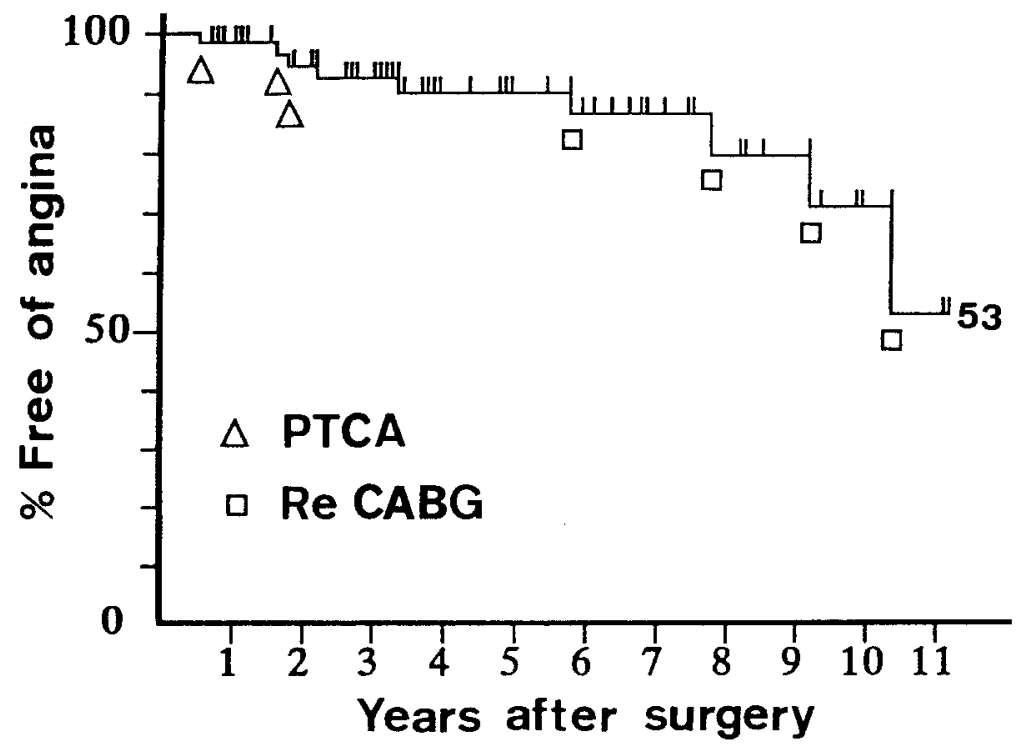

Fig. 2. Actuarial freedom from recurrent angina after CABG in the patients with FH. PTCA, Percutaneous transluminal coronary angioplasty; $\operatorname{Re} C A B G$, repeat coronary artery bypass grafting. Short vertical lines along the course of the solid lines indicate individual patients who were followed up after CABG. The symbols for PTCA and Re CABG are positioned at the time of the re-intervention.

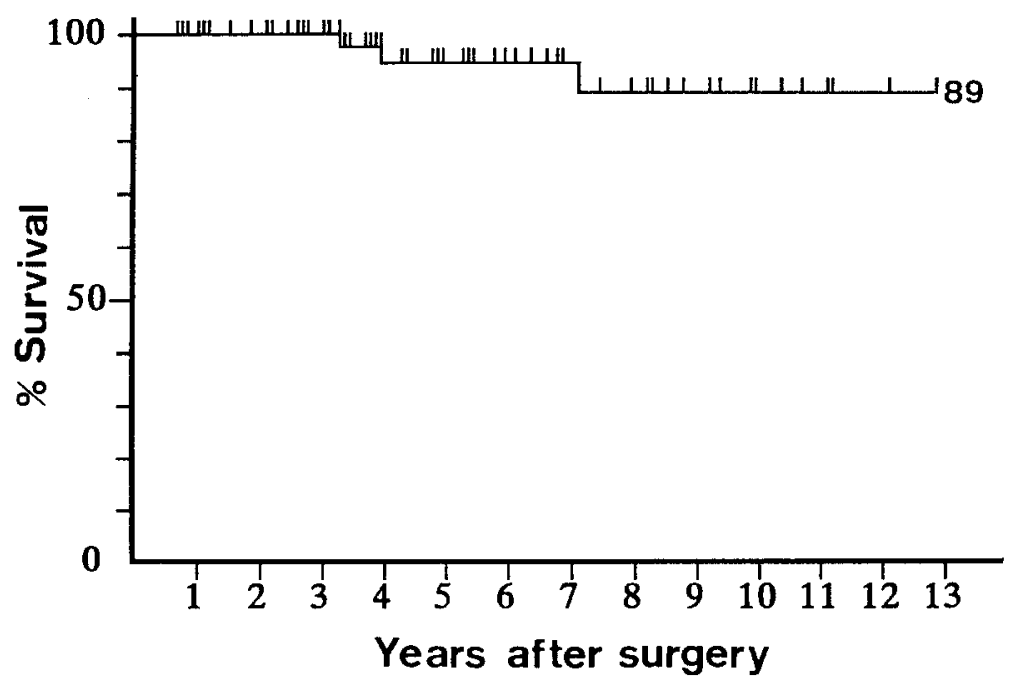

Fig. 3. Actuarial survival of the patients with FH who underwent CABG. Short vertical lines along the course of the solid lines indicate individual patients who were followed up after CABG.

stenosis index increased from 8.5 after the first operation to 17.3 before the second operation. None of the patients who received internal thoracic artery graft underwent reoperation. None of the seven patients who underwent LDL apheresis had recurrent angina for as long as 7 years. There was no cardiac death during the follow-up period, but three patients died of pancreatic cancer, leukemia, and lung cancer, 3, 4 and 7 years after CABG. The actuarial survival rate was $95 \%$ at 5 years after the initial operation and $89 \%$ at 12 years (Fig. 3).

\section{Discussion}

A substantial body of evidence exists that supports the concept that high LDL cholesterol level is an independent risk factor for coronary atherosclerosis. ${ }^{13-16}$ Nonlipid coronary risk factors, such as hypertension, diabetes, cigarette smoking, and obe- 
sity, appear to be overridden by the more marked risk factor of hereditary hypercholesterolaemia. ${ }^{6,7}$ Patients with FH constitute a homogeneous group of patients with regard to the relationship between hypercholesterolaemia and coronary atherosclerosis and are therefore a good model for evaluating the long-term outcome after CABG.

Mabuchi and associates ${ }^{6}$ estimated that coronary stenosis in male and female patients with heterozygous FH begins at 17 and 25 years of age, respectively, and that the coronary stenosis index reaches 20 at 56 and 69 years of age, respectively. They showed that the age at which the coronary stenosis index reaches 20 coincides with that at death. The patients with $\mathrm{FH}$ in the present study had severe coronary atherosclerosis, as shown by the mean coronary stenosis index of 19.7. The proximity of this value to 20 suggests that the patients were at risk of death. Comparative angiographic studies have shown that the coronary atherosclerosis in patients with $\mathrm{FH}$ is more extensive and severe than that in non-FH patients without FH. ${ }^{9,11}$ Distal coronary artery segments often show diffuse atherosclerotic change, and complete myocardial revascularization is difficult in some FH patients. Because of its high incidence, coronary ectasia has been reported as a characteristic coronary angiographic finding in $\mathrm{FH}$ patients. ${ }^{11}$

Various extracoronary atherosclerotic lesions are present in patients with $\mathrm{FH}$. Although severe atheroma of the aortic valve and root is considered to be a characteristic feature of homozygous $\mathrm{FH},{ }^{8}$ Ribeiro and associates ${ }^{17}$ found that some patients with heterozygous $\mathrm{FH}$ had severe supravalvular aortic changes similar those with homozygous $\mathrm{FH} .{ }^{17}$ Four of the patients in the present study had supravalvular aortic stenosis, but these lesions were not hemodynamically significant. Four patients who underwent reoperation showed severe atherosclerosis of the ascending aorta, which required special attention to proximal anastomosis of bypass grafts. Kita and associates ${ }^{18}$ reported that the prevalence of abdominal aortic aneurysm in patients with $\mathrm{FH}$ was $26 \%$. It is therefore important to evaluate the abdominal aorta and its branches in patients with FH in whom the right gastroepiploic artery is considered for use as a bypass graft. Nine patients had symptomatic atherosclerotic disease of the lower extremities. A study with Doppler echocardiography showed that peripheral arterial diseases were more frequent among patients with $\mathrm{FH}$ than in a control group. ${ }^{19}$ Curiously, cerebral infarction is not a characteristic feature of patients with $\mathrm{FH}^{20}$
The internal thoracic and right gastroepiploic arteries have been used as bypass conduits, with the expectation of superior long-term patency. ${ }^{21,22}$ In spite of the high prevalence of extracoronary atherosclerotic lesions in patients with $\mathrm{FH}$, the internal thoracic and right gastroepiploic arteries show no histologic differences from those in patients without $\mathrm{FH}^{23}$ This findings suggest that a good long-term patency rate can be obtained with arterial grafts in patients with $\mathrm{FH}$. We have used arterial grafts in 97\% of our patients with $\mathrm{FH}$ during the most recent 4-year period. The cause of reoperation was vein graft atherosclerosis; thus, we believe that arterial grafts should be used intensively to promote graft patency and to reduce the prevalence of reoperation.

Plasma cholesterol level affects atherosclerosis progression both in native coronary arteries and in bypass grafts. The Cholesterol-Lowering Atherosclerosis Study showed that active lowering of LDL cholesterol level with combined colestipol-niacin therapy decreased atherosclerosis progression and increased regression in native coronary arteries and also reduced new lesions in bypass grafts. ${ }^{14,15}$ Intensive lipid-lowering drug therapy reduced the frequency of progression of coronary lesions, increased the frequency of regression in men with coronary artery disease, and elevated apolipoprotein B (or LDL cholesterol) level in patients with a family history of coronary artery disease. ${ }^{24}$ The coronary atherosclerosis in patients with $\mathrm{FH}$ progresses more rapidly than that in the general population. ${ }^{1,2,6,7}$ In patients with $\mathrm{FH}$ who are relatively young, cholesterol-lowering therapy is important to retard coronary atherosclerosis for a prolonged period after CABG. Cholesterol-lowering diet and drug therapy are mandatory and, when these are ineffective, plasma LDL apheresis is indicated. In the present study, intensive cholesterol-lowering therapy including drug therapy and LDL apheresis reduced plasma total cholesterol level by $37 \%$, LDL cholesterol level by $42 \%$, and LDL/HDL cholesterol ratio by $37 \%$; and this therapy reduced cholesterol levels for a long time. The actuarial survival rate of the patients with $\mathrm{FH}$ who underwent CABG in this study was as high as the survival probability after $C A B G$ in a heterogeneous groups of patients..$^{25,26}$ Although angiographic assessment was not conducted in this study, the good long-term results suggest that intensive cholesterol-lowering therapy effectively retards atherosclerosis progression in patients with $\mathrm{FH}^{27}$

The present study showed that, although the patients with FH had severe coronary and extra- 
coronary atherosclerotic lesions, they underwent CABG with a low mortality rate. The present findings suggest frequent use of arterial grafts and intensive cholesterol-lowering therapies including combined drug therapy and LDL apheresis, and the good long-term results suggest that $\mathrm{CABG}$ should be performed in patients with FH. However, further long-term follow-up is necessary.

\section{REFERENCES}

1. Goldstein JL, Brown MS. Familial hypercholesterolemia. In: Sturnbury JB, Wyngarden JB, Fredrickson DS, Goldstein JL and Brown MS, eds. The metabolic basis of inherited disease. 5th edition. New York: McGraw-Hill, 1983:672-712.

2. Jensen J, Blankenhorn DH, Kornerup V. Coronary disease in familial hypercholesterolemia. Circulation 1967;36:77-82.

3. Mabuchi $\mathbf{H}$, Miyamoto S, Ueda $\mathrm{K}$, et al. Causes of death in patients with familial hypercholesterolemia. Atherosclerosis 1986;61:1-6.

4. Mabuchi H, Tatami R, Haba T, et al. Homozygous familial hypercholesterolemia in Japan. Am J Med 1987;65:290-7.

5. Slack J. Inheritance of familial hypercholesterolemia. Atherosclerosis Rev 1979;5:35-66.

6. Mabuchi H, Koizumi J, Shimizu M, Takeda R, Hokuriku FH, CHD Study Group. Development of coronary heart disease in familial hypercholesterolemia. Circulation 1989;79:225-32.

7. Heiberg A. The risk of atherosclerotic vascular disease in subjects with xanthomatosis. Acta Med Scand 1975;198:246-61.

8. Allen TM, Thompson GR, Myant NB, Sterner R, Oakley CM. Cardiovascular complications of homozygous familial hypercholesterolemia. Br Heart J 1980; 44:361-8.

9. Kawasuji M, Kawajiri F, Watanabe G, Matsunaga Y, Tedoriya $T$, Iwa $T$. Coronary bypass surgery for familial hypercholesterolemia. Jpn J Thorac Surg 1988;41:537-40.

10. Austen WG, Edwards JE, Frye RI, et al. AHA committee report: a reporting system on patients evaluated for coronary artery disease. Circulation 1975;51:7-40.

11. Genda A, Nakayama A, Shimizu M, et al. Coronary angiographic characteristics in Japanese patients with heterozygous familial hypercholesterolemia. Atherosclerosis 1987;66:29-36.

12. Koizumi J, Koizumi I, Ueno Y, et al. Reduction of lipoprotein(a) by LDL-apheresis using a dextran sulfate cellulose column in patients with familial hypercholesterolemia. Atherosclerosis 1993;100:65-74.

13. Kannel WB, Schazkin A. Risk factor analysis. Prog Cardiovase Dis 1983;26:309-32.

14. Lipid Research Clinics Program. The Lipid Research
Clinics Coronary Primary Prevention Trial results. I. Reduction in incidence of coronary heart disease. JAMA 1984;251:351-64.

15. Lipid Research Clinics Program. The Lipid Research Clinics Coronary Primary Prevention Trial results: II. The relationship of reduction in incidence of coronary heart disease to cholesterol lowering. JAMA 1984; 251:365-74.

16. Frick MH, Elo O, Haapa K, et al. Helsinki Heart Study: primary prevention trial with gemifibrotil in middle-aged men with dyslipidemia: Safety in treatment, changes in risk factors, and incidence of coronary heart disease. N Engl J Med 1987;317:1237-45.

.17. Ribeiro P, Shapiro LM, Gonzalez A, Thompson GR, Oakley CM. Cross-sectional echocardiographic assessment of the aortic root and coronary ostial stenosis in familial hypercholesterolemia. Br Heart J 1983; 50:432-7.

18. Kita Y, Shimizu Y, Sugihara N, et al. Abdominal aorta aneurysm of familial hypercholesterolemia. $\mathrm{J}$ Jpn Coll Angiol 1991;31:307-12.

19. Rubba P, De Simone B, Postiglione A, Cortese C, Gnasso A, Mancini M. Extracoronary athetosclerosis in familial hypercholesterolemia. Atherosclerosis 1988; 71:205-13.

20. Kaste M, Koivisto P. Risk of brain infarction in familial hypercholesterolemia. Stroke 1988;19:1097100.

21. Loop FD, Lytle BW, Cosgrove DM, et al. Influence of the internal mammary artery graft on 10-year survival and other cardiac events. N Engl J Med 1986;314:1-6.

22. Pym J, Brown PM, Charrette EJP, Parker JO, West RO. Gastroepiploic-coronary anastomosis: a viable alternative bypass graft. J THORAC CARDIOVASC SURG 1987;94:256-9.

23. Tedoriya T, Kawasuji M, Sakakibara N, Ueyama K, Takemura $\mathrm{H}$, Watanabe Y. Coronary artery bypass surgery in patients with familial hypercholesterolemia. Jpn J Thorac Surg 1992;40:1095-9.

24. Brown G, Albers JJ, Fischer LD, et al. Regression of coronary artery disease as a result of intensive lipidlowering therapy in men with high levels of apolipoprotein B. N Engl J Med 1990;323:1289-98.

25. Varnauska E, The European Coronary Surgery Study Group. Twelve-year follow-up of survival in the randomized European Coronary Surgery Study. N Engl J Med 1988;319:332-7.

26. Alderman El, Bourassa MG, Cohen LS, et al. (CASS Investigators). Ten-year follow-up of survival and myocardial infarction in the randomized Coronary Artery Surgery Study (CASS). Circulation 1990;82: 1629-47.

27. Kane JP, Malloy MJ, Ports TA, Phillips NR, Diehl JC, Havel RJ. Regression of coronary atherosclerosis during treatment of familial hypercholesterolemia with combined drug regimens. JAMA 1990;264:300712. 